\title{
Prevalence of Intestinal Parasites from Abattoir Effluents in Jos Metropolis, Nigeria
}

\author{
Victoria Daminabo' ${ }^{\text {, James Damen }}{ }^{2}$ \\ ${ }^{1}$ Department of Science Laboratory Technology, School of Science and Technology, Captain Elechi Amadi Polytechnic, Port Harcourt, \\ Nigeria \\ ${ }^{2}$ Department of Medical Microbiology and Parasitology, Jos University Teaching Hospital, Jos, Nigeria
}

Email address:

vicjodish@yahoo.co.uk (V. Daminabo)

\section{To cite this article:}

Victoria Daminabo, James Damen. Prevalence of Intestinal Parasites from Abattoir Effluents in Jos Metropolis, Nigeria. International Journal of Photochemistry and Photobiology. Vol. 4, No. 1, 2020, pp. 1-10. doi: 10.11648/j.ijpp.20200401.11

Received: November 28, 2019; Accepted: December 25, 2019; Published: January 7, 2020

\begin{abstract}
This study was carried out to determine the prevalence of intestinal parasites from abattoir effluents. A total of 200 samples were examined out of which 50 samples each from Goat, Sheep, Pig and Cow respectively. These samples were processed using standard parasitological techniques including macroscopy, microscopy; formol ether concentration and modified Ziehl Neelsen method. Out of the 200 samples examined 109 where positive for intestinal parasites. This result revealed an overall prevalence of 54.5\% in all. A total of $30(60 \%)$ was recorded for goat, 23 (46.0\%) cow, 29 (58.0\%) sheep and $27(54.0 \%)$ pigs. The prevalence of different parasites encountered included Ascaris suum (5.6\%), Trichuris trichiura (3.2\%), Hookworm (24.2\%), Strongyloides stercolaris (0.8\%), Teania spp. (2.8\%), Enterobius vermicularis (7.1\%) Trichostrongylus (8.3\%), Diphyllobothrium latum (0.4\%), Schistosoma intercalatum (0.1\%), Fasciolopsis buski (8.3\%), Fasciola hepatica (3.2\%) and Metagonimus yokogawai (0.4\%). Others were Paragonimus westermani (0.4\%), Entamoeba coli (9.9\%), Entamoeba histolytica (6.7\%), Giardia lamblia (4.4\%), Trichomonas hartmani (0.8\%), Balantidium coli (11.1\%) and Oocyst of Crypstoporidium (2.0\%). The highest prevalence was hookworm (42.6\%) in goat and Balantidium coli (60.7\%) in pigs. Fasciolopsis buski and Metagonimus yokogawai had the lowest prevalence $(0.4 \%)$. There was a significant prevalence of intestinal parasites in effluents of Jos Abbatoir.
\end{abstract}

Keywords: Intestinal Parasites, Abattoir Effluents, Prevalence, Jos, Hookworm, Goat, Sheep, Pig, Nigeria

\section{Introduction}

Parasites are organisms that obtain their food from other living creatures. A well-adapted parasite does not kill its host because it depends on the host for a steady supply of food over a long period of time. Usually, parasites are smaller than their host and this distinguishes them from predators such as tigers, which also eat other living things. Some parasites live in only one species of animal but many parasites, particularly the worms, spend part of their lives reproducing sexually in a final or definitive host and developing asexually as larvae during another part of their life in an intermediate host of a different species [1].

It has been estimated that humans harbour about 300 species of parasitic worms and over 70 species of them are protozoa $[2,3]$. Many of these parasites have coexisted for thousands of years and have been identified among human by
Archaeologists [4]. We may have inherited some parasites from our primate ancestors, while others were acquired from companion and food animals. Not all parasites are foodborne and some are very rare [4]. Intestinal parasites are very common problems among humans and animals. The two main types of intestinal parasites include protozoa and helminths. Protozoa are single-celled organisms and can multiply within the body, and this includes Amoeba, flagellates, ciliates, microsporidia and coccidia.

Helminths are parasites-such as Tapeworms, Roundworms, and ringworms. These organisms can be found in the air, water and food. They can attach themselves to internal organs and cause serious damage to the human body $[5,6]$. Intestinal parasites of medical importance to man include Enterobius vermicularis, the soil-transmitted helminthes (STH); Ascaris lumbricoides, Trichuris trichiura, hookworms (Necator americanus and Ancylostoma 
duodenale) and Strongyloides stercoralis and the protozoa Entamoeba histolytica and Giardia duodenalis [7]. Other protozoa such as Cryptosporidium sp. and Isospora sp. are becoming important in causing prolonged diarrhoea in immuno-compromised patients. It is estimated that between 500 million and 1 billon people worldwide are infected by nematode species such as Ascaris lumbricoides, Trichuris trichiura and hookworms [7]. Most of the infections are endemic and widely distributed throughout poor and socioeconomically deprived communities in the Tropics and Subtropics. Environmental, socio-economic, demographic and health-related behaviour is known to influence the transmission and distribution of these infections [7].

Infections in domestic ruminants are of special concern because of the potential contamination of surface and ground-waters through abattoir effluents, pasture runoff and use of manure as a spray on fields. Outbreaks from waterborne Giardiasis in humans have been attributed to pasture run off leading to drinking water contamination [8]. Disease outbreaks have most often been attributed to the waterborne method of transmission [9]. It is believed that human effluent is the major source of water contamination, but certainly contamination of water with infected animal faeces as is the case with abattoir effluents can lead to widespread infections in human and animals $[8,10]$.

Food-borne infections have been associated with poor hygiene in food handlers and washing food with contaminated water [8]. This is a particular concern as water is important in the processing of many foods. The cysts of parasites have a protective carbohydrate wall that makes them resistant to environmental destruction [8] and are only destroyed by desiccation, heat, UV radiation and high concentrations of biocides [8, 11]. Abattoir effluents and runoffs to varying extents are incorporated into the soil. These wastes can also enter water systems by direct contamination of the water or through seepage or surface runoff.

Humans contaminate water sources through poorly processed sewage effluents, malfunctioning septic tanks and seepage from sanitary landfills. Failure to appropriately process abattoir effluents probably poses a threat to human health although it is often difficult to identify sources of food and water contamination. A study conducted in Southern Sudan by Magambo et al. [12] show that proximity to wastewater constitutes an infection hazard by Ascariasis. This is supported by the results of an epidemiologic study of a group of children living near an area of wastewater effluents. The risk attributable to wastewater in transmitting Ascariasis to children in Sidi Daoui was about $17 \%$. The present study was aimed to determine the prevalence of intestinal parasites from abattoir effluents in Jos Metropolis, Plateu State of Nigeria.

\subsection{Prevalence of Intestinal Parasites}

There are 3200 varieties of parasites in the four major categories, Protozoa, Trematoda, Cestoda, Nematoda, intestinal helminths and protozoa infestations in humans. The prevalence shows correlation with the methods of faecal disposal and personal hygiene [13-16], and was reported and noted that incidence among developing countries are common [16-20].

\subsection{Prevalence of Intestinal Parasites in Goats}

Trichuris species have been observed frequently in Goats $[20,21]$. Trichostrongylus species are one of the major agents of gastrointestinal nematodosis in goats [20]. Pathak and Pal [24] reported an overall prevalence of $(85.22 \%)$ Gastrointestinal parasitosis in goats, with Trichuris sp having a prevalence of $27.27 \%$ and Trichostrongylus having a prevalence of 5.68 percent respectively.

\subsection{Prevalence of Intestinal Parasites in Cattle}

Many cattle are overworked and most of them underfed or half fed during most of the time of the years. They are not supplied with adequate balanced ration. As a result the general nutritional status of most of the cattle is in subnormal level, which greatly increases susceptibility to parasitic diseases [25, 26]. Sadar et al [27] reported high infection rates of Fasciola, Trichuris and Schistsoma, Ascaris and Strongyloides were also reported.

\subsection{Prevalence of Intestinal Parasites in Sheep}

The major intestinal parasites of sheep are round worms (nematodes), which infect the stomach and intestinal tract; tapeworms; lungworms and liver flukes of these, nematodes cause the most economic loss. Sheep have often been assumed to be an important reservoir for human infection via both direct transmission and contamination of water catchment areas, effluent, and possibly abattoirs.

\subsection{Prevalence of Intestinal Parasites in Pigs}

Teania solium has not been reported in Canadian pigs for over two decades. In Canada, Teania solium infection is a reportable disease. It is a common parasite of pigs in developing countries. Giardia is a common parasite of wild and domesticated animals. It has been demonstrated in pigs in Canada, United States and in Europe. Giardia was reported in four (4) of six (6) Hog operations with overall prevalence of 9\% [23-25]. In a large Alberta study involving 1602 animals (pigs) and 50 farms, Giardia was documented in $70 \%$ of farms and in $8.5 \%$ of fecal samples. Giardia cysts were identified in $3.8 \%$ of piglets, $9.8 \%$ of weaners, $10.8 \%$ of growers, $15 \%$ of finishers, $5.7 \%$ of Boars and $4.1 \%$ of sows [26]. A significant proportion of feral pigs $(7.6 \%)$ in California have been shown to infect with Giardia [27].

Although there a few studies, cryptosporidium has been demonstrated in pigs throughout the world. In a Canadian study, Cryptosporidium was identified in 3 of 4 sampling sites with an overall prevalence of $11 \%$ [26]. In a larger Alberta study, cryptosporidium was demonstrated in $32 \%$ of 50 farms sampled with a $2.8 \%$ overall prevalence. Infection was predominantly in weaners. Balantidium coli is widely distributed in pigs, particularly in warm and temperate 
climates. Balantidium coli inhabits the large intestine of man, monkeys and pigs, where the trophozoites feed on cell debris of the intestinal wall, starch grains, bacteria and mucus as lumen parasites.

It is generally believed that pigs act as the main reservoir for human infections. Toxoplasma has been demonstrated in pigs worldwide. Serological testing of pigs in the United States and Canada have shown sero-prevalence between 3.5 to $48 \%$ [28, 29]. Infection in pigs is associated with exposure to cat and contaminated soil [30]. In Saskatchewan examination of up to $50 \%$ of abattoir pig livers demonstrated, scrarring associated with migration of Ascarid larvae [19]. Ascaris suum eggs under dry conditions survive for two to four weeks while under a moist and cool environment they can survive for over 8 weeks [31-34].

\subsection{Epidemiology}

Epidemiology is the study of patterns of infection and disease within populations or defined communities [35]. A higher infection rate has been observed in children than adult and in males than female [36-38], due to their exposure to the source of infection, low hygienic standard and lack of education on route of infection with prevalence and severity of infection high in developing countries where health and sanitary facilities are unable to cope with the demands of increasing population with main burden been borne by young children with adverse effect on their physical and mental development which may be long lasting [13]. Indiscriminate eating habit, due partly to poverty poor personal and environmental hygiene also contributes to the prevalence of this parasite since infection is achieved through a range of food stuff example fresh vegetable eaten raw [39]. Through contaminated unwashed fingers, cyst or ova are being spread by flies and other animals, circulating banknotes.

A warm humid with shade climate is also a basic factor coupled with the indiscriminate defecation by people, disposal of abattoir effluent and the use of untreated human excreta to enhance soil fertility, this helps in the development of various stages and in the dispersal of the cyst and ova. Inhalation and dissemination of ova is also possible from polluted soil under dry conditions. Likewise domestic pigs, and dogs eat fresh human faeces and act as reservoir host and source of infection to man. Abattoir effluents and runoffs to varying extents are incorporated into the soil and constitute waste water.

\subsection{General Life Cycle and Pathology}

\subsubsection{Intestinal Protozoa}

Understanding the life cycle is essential to explain the pathophysiology of the diseases caused by protozoa. The life cycles of intestinal protozoa are very similar, with the exception of Dientamoeba fragilis, which lacks a cyst stage [40-43]. All intestinal protozoa undergo direct life cycle [43, 44]. They exhibit life cycle alternating between active growing forms (trophozoites) and resting stage (cysts). The resulting stages are responsible for the transmission of infection [44].

The infection spreads from person to person indirectly via contaminated vegetables, food or water. Within the small intestine, the cyst wall breaks down and excyst and develop into trophozoites (invasive forms). The trophozoites move into the large intestine where they multiply by binary fission and periodically form new cysts. Each cyst gives rise to eight trophozoites. The cyst can also mature within the host or outside the environment $[45,46]$.

\subsubsection{Intestinal Nematodes}

The life cycle of parasitic nematodes is clinically important. Some nematode infections can be transmitted directly from infected to uninfected people; in others, the nematode eggs must undergo a process of maturation outside the host. In a third category, the parasites may spend a part of their life cycle in the soil before becoming infective to humans $[47,48]$. The intestinal nematodes undergo a direct life cycle not involving intermediate host.

In the simplest type of life cycle e.g Enterobius vermicularis, embryonated eggs are ingested by the host and hatch in the intestine where they reach maturity, only burying themselves temporarily in the mucus membrane. Disease of E. Vermicularis is relatively innocuous, with egg deposition causing perineal, perianal, and vaginal irritation. The patient's constant itching in an attempt to relieve irritation can lead to potentially debilitating sleep disturbance. Rarely, more serious disease can result, including weight loose, urinary tract infection, and appendicitis [49]. Some directly developing species e.g Ascaris lumbricoides, after hatching in the intestine undergo tissue migration through the body returning to become established in the intestine. The simple type of life cycle represented by Ascaris may be varied in other species by the first-stage embryo hatching outside the body, developing to an infective larva, and re-infecting its host by skin penetration [50-53]. In yet another type of life history, there may be an alternation of a parasitic generation with a free living one. The best known is those of various species of the genus Strongyloides, in which the free larvae may develop to free living adults if the external environment is suitable [54]. In the intestine, the parasite grows and develops into adult male and female which lay eggs after mating when matured. The adults attach to the mucosa of the host and inhabit the intestine for as 140 years as in Hookworm, 1-2 months as in Enterobius vermicularis and about 12 months for Ascaris lumbricoides [55].

The severity of infections caused by worms which do not divide within the host is proportional to the number of infecting worms e.g Ancylostoma duodenale (Hookworms) which attach to the intestinal wall, consumes about $0.25 \mathrm{ml}$ of host blood per day. The blood by hookworms can produce microcytic hypochromatic anaemia. Compensatory volume expansion contributes to hypoproteinemia, edema, pica, and wasting. The infection may result in physical and mental retardation in children. Eosinophilia has been noted in 30 to 60 percent of infested patients. Strongyloides stercoralis can overwhelm an immunosuppressed host by its capacity to 
undergo autoinfection in humans [50, 54-57].

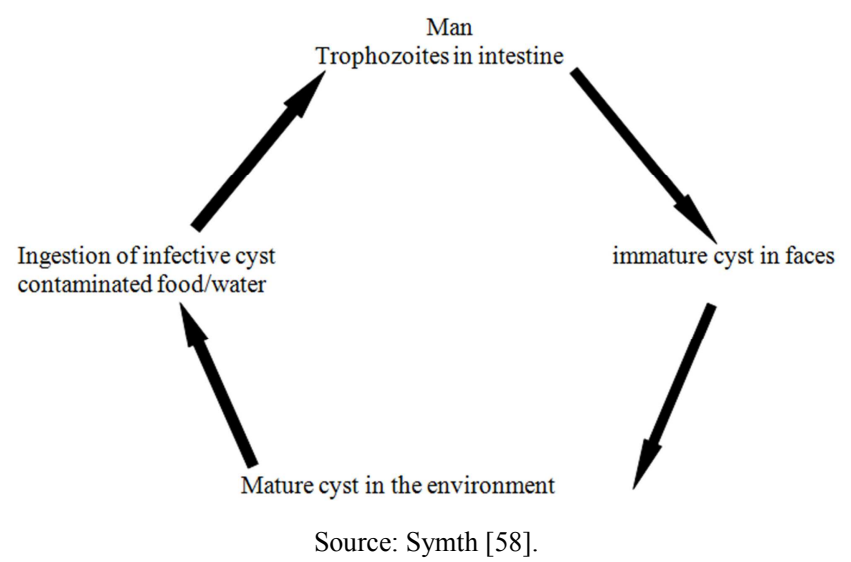

Figure 1. Diagramatic representation of life cycle of intestinal protozoa.

\subsubsection{Intestinal Cestodes}

A tapeworm larval cyst (cysticercus) is ingested with poorly cooked infected meat; the larva escapes the cyst and passes to the small intestine where it attaches to the mucosa by the scolex suckers. The proglottids develop as the worm matures in 3 to 4 months. The adult may live in the small intestine as long as 25 years and pass gravid proglottids with the faeces. Eggs extruded from the proglottid contaminate and persist on vegetation for several days and are consumed by cattle or pigs in which they hatch and form cysticerci [56]. Gastrointestinal symptoms are due to the presence of the tape worm. Cysticercosis symptoms are a result of inflammatory/immune responses. Antibodies are produced in cysticercosis and are useful epidemiological tools [59].

\subsection{Laboratory Diagnosis of Intestinal Parasites}

Generally, the laboratory diagnosis of intestinal parasites is based on stool examination for worms, eggs, cysts, trophozoites segments of cestodes etc. In the stool examination, two methods are normally used: direct wet preparation and concentration methods. In Giadiasis, diagnosis by identification of cysts or trophozoites in the faeces, using direct wet mount as well as concentration, procedures. In addition, sample or duodenal fluid (e.g. enterotest) or duodenal biopsy may demonstrate trophozoites.

Alternate methods for detection include antigen detection of parasites by immunoassays and detection of parasites by immunoflurescence test [42]. However, Entemoeba histolytica can be diagnosed by microscopic identification of cysts and trophozoites in the stool using direct mounts as well as concentration procedures. In addition, Entamoeba histolytica can also be identified in aspirates or biopsy samples obtained during colonoscopy or surgery [42]. Apart from the stool examination, infection by intestinal parasites can be discovered by culturing the stool sample on culture media like Balamuth Monophasic, medium for Entamoeba histolytica, Dobell and laid cow's medium Horse serum egg medium for flagellates and Amoeba.

Cryptosporidium parvum can be identified by the stool examination using direct mount as well as concentration procedures using floatation technique and formol ether techniques. A staining procedure have been employed for demonstration of oocytes of Cryptosporidium parvum in the faecal smear using modified and fast staining method (Modified ZN stain method). Red stain oocysts can also be demonstrated in the sputum, bronchial washings and duodenal or jejuna aspirations using modified acid fast staining method (Modified ZN stain method).

Antibodies specific to Cryptosporidium parvum can be detected by IFA assays using endogenous stages of the parasite in tissue section as antigens [36]. Pinworm infection can be diagnosed by direct visualization of the adult worm or microscopic detection of eggs. The "cellophane tape test" can serve as a quick way to clinch the diagnosis. This test consists of touching tape to the perianal area several times, removing it, and examining the tape under direct microscopy for eggs [52].

\subsection{Prevention and Control}

It is obvious that no significant reduction in disease due to intestinal parasites can be achieved until living conditions, sanitation and water supplies are improved. There are however, compelling reasons for targeting antihelminthics against particular groups in communities where the infections are highly endemic [59]. The ultimate eradication of infection in a community must depend on the improvement of general standard of sanitation through installation of suitable sewage treatment and disposal facilities and provision of permanent pipe-born water supply, since the infection is sustained by faecal contamination of the soil and water.

Meat inspection, adequate cooking of fish, beef, and pork destroying of the snail intermediate host do a lot in reducing trematode and cestode infection [58]. Periodic treatment with effective antihelminthic can markedly reduce the prevalence of infection in the community [12]. The world health organisation (WHO) now advised that children need treatment to relieve them from the effects of intestinal helminth infection [18]. Generally, the intestinal parasites of man can be controlled by the following means:

i. Washing hands often when exposed to public facilities.

ii. Washing hands after cutting animals' flesh.

iii. Limiting all animals' flesh consumption, particularly, undercooked or raw flesh.

iv. Avoid drinking untested wild water supplies.

v. Cleaning of all pets and household members together.

Treatment of intestinal nematodes of Ascalis lumbricoides, Trichuris trichiura and the Hookworms can be achieved by using benzimidazole derivatives, albendazole and mebendazole. Albendazole is given a single dose of $400 \mathrm{mg}$ and although mebendazole has traditionally been given a $100 \mathrm{mg}$ tablet $2 \mathrm{x}$ daily 3 days, two other drugs levamisole and paraziquantel are also used to treat mixed infections with hookworm and Ascaris lumbricoides but is associated with side effect. 


\section{Materials and Methods}

\subsection{Study Area}

This study was carried out in abattoir located at Gigiring in Jos, the capital of Plateau State which is located in middle belt of Nigeria. It comprises of various ethnic groups such as Berom, Afizere, Anaguta, Hausa, Ibos, Yoruba and fulanis. Their occupation ranges from peasant farmers, traders, civil servants etc.

\subsection{Sample Collection}

A total number of 200 effluent samples were collected randomly from four different species of animal slaughtered in the Abbatoir, they includes cow, goat, sheep and pig. Fifty samples each were collected from these animals. All samples were collected in clean transparent, wide mouth screw capped universal bottle for laboratory processing. All specimens collected were properly numbered and labelled appropriately.

\subsection{Examination of Wet Preparation}

A drop of suspended sediments in saline was placed on the centre of clean grease free slide and covered with a cover slip. The preparation was examined using x10 and $\mathrm{x} 40$ objectives lenses of the microscope with the iris diaphragm closed and condenser lowered [13].

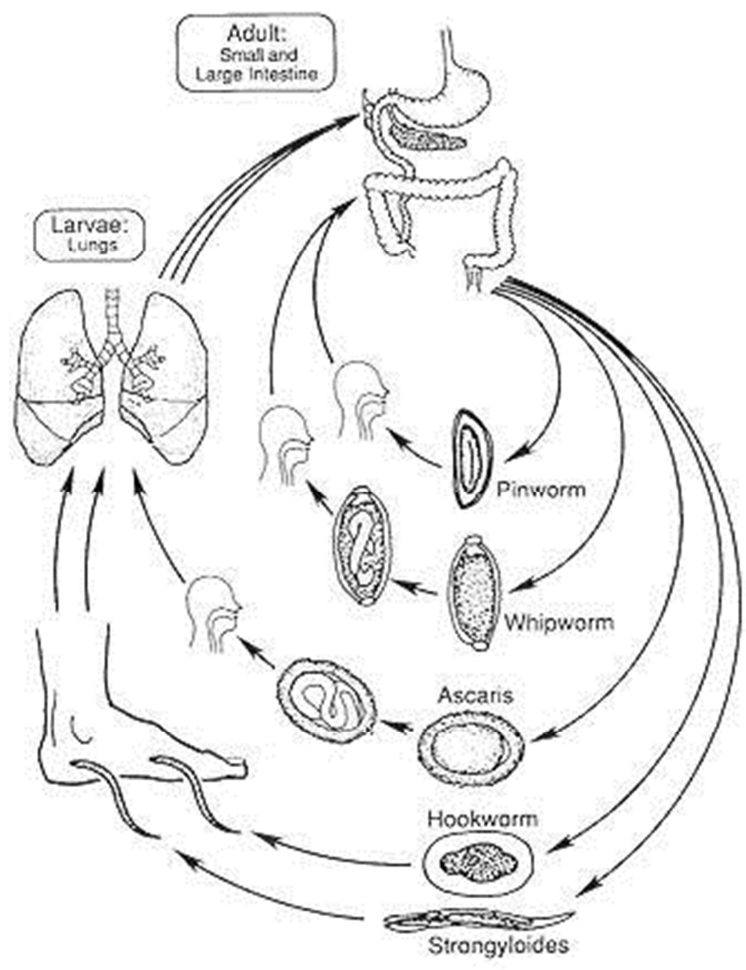

Source: Abdul [22]

Figure 2. Diagrammatic representation of life cycle of intestinal nematodes.

\subsection{Iodine Preparation}

Iodine mount was prepared by the addition of a drop of iodine to a drop of the deposit placed on a clean grease free slide. The preparation was covered with cover slip and examined using x10 and $\mathrm{x} 40$ objectives lenses of the microscope, with the iris diaphragm closed and condenser covered [13-15].

\subsection{Formol Ether Concentration Technique}

Seven mls of formol water was added into screw cap bottle. One gram of well-mixed faecal Sample was emulsified into the tube and filtered by passing through a wet gauze into a centrifuge tube. Three mls of diethyl ether was centrifuged at $3000 \mathrm{rpm}$ for 1 minute. The debris layer was loosened using an applicator stick and the whole supernatant discarded into disinfectant jar. The deposit was loosened by tapping the tube between the fingers and a drop of the sediment placed on the center of a clean grease free glass slide and a cover slip applied gently to avoid air bubbles and over flooding. The preparation was examined with $\mathrm{x} 10$ and $\mathrm{x} 40$ objectives.

\subsection{Modified Ziehl Neelsen (ZN) Method}

A smear was prepared from the sediment obtained by the formol-ether concentration technique [6]. The smear was allowed to air-dry. The smear was fixed with methanol for 3 minutes; the smear was stained with unheated carbol-fuchsin for 15 minutes. The smear was washed off with water. The smear was decolourised with $1 \%$ acid alcohol for 10 seconds. The smear was washed, counterstained with $0.5 \%$ methylene blue for 30 seconds. The smear was washed off with water and the slide was allowed to dry. The smear was examined microscopically for oocysts using X10 and X40.

\section{Results}

A total of 200 abattoir effluent samples were collected and examined for intestinal parasites, out of which 109 samples were positive of intestinal parasites giving a prevalence of $54.5 \%$. The results of this research are presented in the following Tables: Table 1shows prevalence of intestinal parasites in effluents from the animals sampled.

Fifty effluent samples from Goat were examined, $30(60 \%)$ were positive. Fifty effluents samples from cow were examined, $23(46 \%)$ were positive. Fifty effluents samples from sheep were examined $29(58 \%)$ were positive fifty effluents samples from pig were examined 27 (54\%) were positive. Table 2 Shows prevalence of individual intestinal parasites. A total of 13 different types of intestinal helminths and 6 different types of intestinal protozoa were isolated. Table 3 shows prevalence of individual intestinal parasites in relation to Animals. This table shows Goat had a higher prevalence of A. suum $26(10.3 \%)$, sheep 19 (7.5\%) for hookworm among others while for protozoa, pigs having a higher prevalence of $17(6.7 \%)$ for B. Coli and Goat $6(2.4 \%)$. Table 4 show the prevalence of Trophozoites, Ova, larva and cyst isolated from animals.

Table 1. Prevalence of Intestinal Parasites $(N=200)$.

\begin{tabular}{llll}
\hline Animal & No. Examined & No. Positive & Prevalence (\%) \\
\hline Goat & 50 & 30 & 60.0 \\
Cow & 50 & 23 & 46.0 \\
Sheep & 50 & 29 & 58.0 \\
\hline
\end{tabular}




\begin{tabular}{llll}
\hline Animal & No. Examined & No. Positive & Prevalence (\%) \\
\hline Pig & 50 & 27 & 54.0 \\
Total & 200 & 109 & 54.5 \\
\hline
\end{tabular}

Table 2. Prevalence of individual Intestinal Parasite $(N=200)$.

\begin{tabular}{lll}
\hline Parasites & No. Positive & Prevalence \\
\hline Ascaris suum & 14 & 5.6 \\
Trichuris trichiura & 8 & 3.2 \\
Hookworm & 61 & 24.2 \\
Strongyloides stercolaris & 2 & 0.8 \\
Teania spp & 7 & 2.8 \\
Enterobius vermicularis & 18 & 7.1 \\
Trichostrongylus & 21 & 8.3 \\
Diphyllobothrium latum & 1 & 0.4 \\
\hline
\end{tabular}

\begin{tabular}{lll}
\hline Parasites & No. Positive & Prevalence \\
\hline Schistosoma intercalatum & 1 & 0.4 \\
Fasciolopsis buski & 21 & 8.3 \\
Fasciola hepatica & 8 & 3.2 \\
Metagonimus yokogawai & 1 & 0.4 \\
Paragonimus westermani & 1 & 0.4 \\
Entamoeba coli & 25 & 9.9 \\
Entamoeba histolytica & 17 & 6.7 \\
Giardia lamblia & 11 & 4.4 \\
Trichomonas hartmani & 2 & 0.8 \\
Balantidium coli & 28 & 11.1 \\
Oocyst of Crypstoporidium & 5 & 2.0 \\
Total & 252 & 100 \\
\hline
\end{tabular}

Table 3. Prevalence of individual intestinal parasite in relation to Animals $(N=200)$.

\begin{tabular}{|c|c|c|c|c|c|c|c|c|}
\hline \multirow[b]{2}{*}{ Parasite } & \multicolumn{2}{|l|}{ Goat } & \multicolumn{2}{|l|}{ Cow } & \multicolumn{2}{|l|}{ Sheep } & \multicolumn{2}{|l|}{ Pig } \\
\hline & $\begin{array}{l}\text { No. } \\
\text { positive }\end{array}$ & $\begin{array}{l}\text { Prevalence } \\
(\%)\end{array}$ & $\begin{array}{l}\text { No. } \\
\text { Positive }\end{array}$ & $\begin{array}{l}\text { Prevalence } \\
(\%)\end{array}$ & $\begin{array}{l}\text { No. } \\
\text { Positive } \\
\end{array}$ & $\begin{array}{l}\text { Prevalence } \\
(\%)\end{array}$ & $\begin{array}{l}\text { No. } \\
\text { positive }\end{array}$ & $\begin{array}{l}\text { Prevalence } \\
(\%)\end{array}$ \\
\hline Ascaris suum & 4 & 28.6 & 4 & 28.6 & 3 & 21.4 & 3 & 21.4 \\
\hline Trichuris trichiura & 5 & 62.5 & 2 & 25.0 & - & - & 1 & 12.5 \\
\hline Hookworm & 26 & 42.6 & 9 & 14.8 & 19 & 31.1 & 7 & 11.5 \\
\hline Strongyloides stercolaris & 1 & 5 & - & 57.1 & - & & 1 & 50 \\
\hline Teania spp & - & 44.4 & 4 & 11.1 & - & 44.4 & 3 & 1.2 \\
\hline Enterobius vermicularis & 8 & 42.9 & 2 & 9.5 & 8 & 47.6 & - & \\
\hline Trichostrongylus & 9 & 100 & 2 & - & 10 & - & - & - \\
\hline Diphyllobothrium latum & 1 & - & - & 0.4 & - & - & - & - \\
\hline Schistosoma intercalatum & - & 2.8 & 1 & 3.6 & 4 & 1.6 & - & 0.4 \\
\hline Fasciolopsis buski & 7 & 0.8 & 9 & 1.6 & 2 & 0.8 & 1 & - \\
\hline Fasciola hepatica & 2 & - & 4 & - & - & - & - & 0.4 \\
\hline Metagonimus yokogawai & - & - & - & 100 & - & - & 1 & - \\
\hline Paragonimus westermani & - & 32.0 & 1 & 36.0 & 4 & 16.0 & - & 16.0 \\
\hline Entamoeba coli & 8 & 35.3 & 9 & 35.3 & - & - & 4 & 29.4 \\
\hline Entamoeba histolytica & 6 & 27.3 & 6 & 45.5 & 2 & 18.2 & 5 & 9.0 \\
\hline Giardia lamblia & 3 & 100 & 5 & - & - & - & 1 & - \\
\hline Trichomonas hartmani & 2 & 21.4 & - & 14.3 & 1 & 3.6 & - & 60.7 \\
\hline Balantidium coli & 6 & 80 & 4 & 20 & - & - & 17 & \\
\hline Oocyst of Crypstoporidium & 4 & & 1 & & & & - & \\
\hline
\end{tabular}

Table 4. Prevalence of Trophozoites, Ova, Larva and Cyst Isolated.

\begin{tabular}{|c|c|c|c|c|c|c|c|c|c|c|c|c|c|}
\hline \multirow{2}{*}{ Parasite } & \multicolumn{3}{|l|}{ Goat } & \multicolumn{3}{|l|}{ Sheep } & \multicolumn{3}{|l|}{ Cow } & \multicolumn{4}{|l|}{ Pig } \\
\hline & Trophozoite & Ova & Cyst larva & Trop & Ova & Cyst & Trop & Ova & Cyst & Troph & Ova & Cyst & Larva \\
\hline Ascaris suum & & 4 & & 1 & 2 & & & 4 & & & 3 & & \\
\hline Trichuris trichiura & & 5 & & & & & & 2 & & & 1 & & \\
\hline Hookworm & & 26 & & & 9 & & & 19 & & & 7 & & \\
\hline Strongyloides stercoralis & & & 1 & & & & & & & & & & 1 \\
\hline Teania spp & & 4 & & & & & & & & & 3 & & \\
\hline Enterobius vermicularis & & 8 & & & 8 & & & 2 & & & - & & \\
\hline Diphyllobothrium latum & & 1 & & & & & & & & & & & \\
\hline Schistosoma intercalatum & & & & & & & & 1 & & & & & \\
\hline Fasciolopsis buski & & 7 & & & 4 & & & 9 & & & 1 & & \\
\hline Fasciola hepatica & & 2 & & & 2 & & & 4 & & & - & & \\
\hline Metagonimus yokogawai & & & & & & & & & & & 1 & & \\
\hline Paragonimus westermani & & & & & & & & 1 & & & & & \\
\hline Entamoeba coli & 4 & & 4 & 2 & & 2 & 6 & & 4 & 2 & & 3 & \\
\hline Giardia lamblia & 2 & & 1 & & & 2 & 4 & & 1 & 1 & & - & \\
\hline Trichomonas hartmani & 2 & & - & - & - & - & - & & - & - & & - & \\
\hline Balantidium coli & 4 & & 3 & 1 & & - & 3 & & 2 & 17 & & 6 & \\
\hline
\end{tabular}

\section{Discussion}

The study shows that of the 200 effluent samples examined, 109 samples were positive for intestinal parasites, giving a prevalence of $54.5 \%$. This finding is higher compared with $3.7 \%$ parasitic liver infection in Ruminants reported by Smyth [60]. This disparity in the prevalence 
might be attributed to the fact that El-Dakhly and colleagues studies was carried out on liver of infected Ruminants. This study also revealed the prevalence of six intestinal protozoan parasites and thirteen intestinal helminths. Fifty effluent samples from goats were examined, $30(60 \%)$ were positive. This prevalence was lower compared with $85.2 \%$ as recorded by Pathak et al. (2008).

The high prevalence recorded by Pathak and associates could have been due to water logging found in and around the pasture lands during which enhance the availability of intermediate hosts, while the low prevalence could be associated with the climatic conditions of Jos which could either be very hot and dry or very cold reduces grazing hours of the animal therefore affecting (reducing) the chances of contact between host and parasites [49].

Fifty effluent samples from cows were examined, 23 (46\%) were positive. This relatively low prevalence could be attributed to seasonal variation which has a direct impact on the qualitative and quantitative assessment of intestinal parasites in cattle as shown in the works of Sayiroli et al [59] Sayiroli's work revealed higher prevalence of cattle parasites in rainy season followed by winter, then summer. The temperature, humidity and rainfall of the countries are highly favourable for parasites. Age and Breed (Native or crossbreed) are also important factors that determine prevalence of parasites in cattle [61].

Fifty effluent samples from sheep were examined, 29 (58\%) were positive, this findings corresponds with $57.5 \%$ prevalence as recorded by Gadahi et al. [28]. These findings might be associated to the fact that infection of sheep lead to impaired immunity and mixed grazing on loose range lands with other animals. The prevalence recorded from this study could also be attributed to mixed grazing as sheep rearing in Jos and environs is mostly carry out in an outdoor manner. Fifty effluent samples from pigs were examined, 27 (54\%) were positive. This study recorded a high prevalence $(60.7 \%)$ of Balantidium coli which agree with a prevalence of $78 \%$ as reported in pig slurries of Alicante (Spain) analyzed by Burton et al (2003).

Burton study was conducted with slurries from intensive farms. Olson et al. [51] recorded the highest prevalence $(47.2 \%)$ with Balantidium coli from pig farms without a strategic anti-parasite treatment regime. In this study area, pigs are rarely raised in intensive farms. Hence infection by parasites could result from loose and uncontrolled foraging. Thus pigs slaughtered at the Jos abattoir could serve as source of zoonotic infections. The finding of this study also shows that Hookworm had the highest prevalence of $24.2 \%$ in effluents obtained from goats. Outdoor breeding of Goats could be in the study area has a significant factor that supports this prevalence. Goats could loosely graze on feacally contaminated forage land hence infection by active penetration of the filariform hookworm larva [36, 37].

Hookworms manifest in Goats as an accidental parasite and possibly result in no disease condition. Balantidium coli recorded a prevalence of $11.1 \%$ from pigs. This finding agrees with the works of Burton et al. [26]. This could be attributed to the fact that pigs are major reservoir hosts for Balantidium coli (Arora and Arora, 2004). The lowest prevalence $(0.4 \%)$ were recorded with Diphyllobotrium latum, Schistoma intercalatum, Metagonimus yokogawai and Paragonimus westermani. Ascaris species has a prevalence of 28.6\% in Goat and Cow, while sheep and pig had 21.4\% prevalence each.

Pathak and Pal [24] emphasized on the importance of grazing hours of animals as regards host-parasite contact. Hence the prevalence of Ascaris in this study could be attributed to indefinite grazing hours as most animals slaughtered in the Jos Abattoir are predominantly from nonintensive systems. Hence these animals are disposed to loose grazing which enhances ingestion of forage contaminated with embryonated eggs of Ascaris. Ingestion of Embryonated egg is an important stage in the developmental life cycle of Ascaris species [13]. In Saskatchewan, examination of up to $50 \%$ of abattoir pig livers demonstrated scarring associated with migration of Ascaris larvae [19]. Ascaris suum eggs under dry conditions survive for two to four weeks while under a moist and cool environment they can survive for over 8 weeks [31]. Hence the prevalence of Ascaris in this study could be related to the weather in the study area. Fasciola hepatica recorded a low prevalence of $1.6 \%$ from cattle and $0.8 \%$ from sheep.

This is in contrast to a study by Guselle and Olson [32] where sheep had a higher prevalence of $(97 \%)$ than cattle (78\%) in Cajamarca; Peru. Though producers in that region recognise fasciolosis as the most common and serious disease affecting their cattle (84\%) and prevalence higher than $90 \%$ has been reported in previous studies. In this study the presence of this parasite could be out of control as it is closely related to climatic conditions. In most cases cattle management practices are inefficient regarding general cattle production and disease prevention and control program with little or non access to technical support (Guselle and Olson, 1999). Taenia specie recorded a high prevalence in cattle $(57.1 \%)$ and low prevalence in pigs $(1.2 \%)$. Guselle and Olson [32] observed that Taenia solium in pigs has not been reported in Canada for over two decades.

Though it is reportable and is a common parasite of pigs in developing countries. From this study improper defecation on loose forage lands in Jos could be a contributing factor in the development of Taeniasis. Also ingestion of improperly cook or raw meat (Beef or pork), meat eaten in form of the traditional barbecue (suya) mostly could contribute. Trichostrongylus presented a prevalence of $42.9 \%$ in Goats and $47.6 \%$ in sheep.

This is comparatively in disagreement with Pathak and Pals work [24] which recorded a high prevalence in Goats (62.5\%). This is in contrast with Pathak and Pals study [24] with goats presenting a prevalence of (27.27\%). Giardia species recorded a prevalence of $27.3 \%$ in goats, $45.5 \%$ in Cow, $18.2 \%$ in sheep and $9.0 \%$ in pigs. This represents a fact that Giardia species are a common parasite of wild and domestic animals. 


\section{Conclusion and Recommendations}

In conclusion the prevalence of parasites in this work is on the high side. This is surprising because the safety of foods obtained from animals for human consumption has become a public health concern. Parasitic infections of animals have a direct effect on them. Intestinal parasites devitalise these animals, robbing them of essential nutrients and injuring their vital organs. The resulting diseases are a major cause of economic loss. The loss of economic value could be a stumbling block in a nation's diplomatic status quo. Generally, poor disease control practices, low level of enlightment, climate, and lack of intensive farming are all predominating factors in the prevalence of intestinal parasites in slaughter animals brought to the Jos Abattoir.

Improper treatment of effluents from the slaughter house, could predispose the neighbouring environment and its in habitants to the risk of contamination and infection by these parasites. Zoonotic transmission of these diseases poses serious threats to man too. Abattoir effluents and runoffs to varying extent are incorporated into the soil. Following indiscriminate slaughter of animals; intestinal parasites harboured by these animals are mixed up and carried in the effluents. Parasite cysts, larvae and trophozoite carried in these effluents directly contaminate the vegetation, the stream and soil around the area.

Ingestion of vegetables contaminated with parasite cysts, ova or larva (Ascaris) could occur, active penetration of the skin by some parasite larva (Hookworm) and the use of the stream for domestic purposes all stand to pose a serious threat to the health of the people who work or reside around the abattoir. Animals that graze on vegetations around the abattoir still pose a serious threat to health as the life cycle of some of the parasites (Teania species) are enhanced by the grazing action of these animals.

Seepage from sanitary landfills should be well processed in functional septic tanks as these will help to check human contamination of water sources, soil and vegetations around the abattoir. From the study, the following recommendations were made. They include the following:

i. The Government to pay more attention to the state of the Abattoir which is a primary facility as regards feeding of a people.

ii. A thorough renovation of the Abattoir with subsequent maintenance policies put in place will be a very welcome development.

iii. Provision of septic (holding) tanks will help in treating effluents from the abattoir prior to disposal. Some parasite cysts have been shown to be degraded when effluents are held in septic tanks hence reducing contamination.

iv. Animals should be well inspected; treated of parasitic diseases (by deworming). It should be ensured that animals are in an apparently health state prior to slaughter.

v. Sanitary measures should be strictly employed as this will help to check environmental contamination. The use of safety boots and other safety wears should be encouraged.

vi. Abattoir staff including butchers should be well enlightened on safety measures to be taken so as to guarantee their state of health.

vii. The public should be enlightened in handling meat/meat products. For instance meats should be properly washed and cooked.

viii. Toilets facilities should be provided for staff and the general public and well situated.

\section{References}

[1] Herwaldt, Bl. (2000). Cyclospora Cayetonensis: A review, focusing on the outbreaks of cycloporiasis in 1990s. Clin Infect Dis 31: 1040-1057.

[2] Orlandi, P. A., Chu, D. M. T., Bier, J. W. and Jackson, G. J. (2002). Parasites and the food supply. Food Technol 56: 7281.

[3] Cox, F. E. G. (2002). History of human parasitology. Clin Microbiol Rev 15: 595-612.

[4] Doyle, E. (2003). Foodborne Parasites: A Review of the Scientific Literature. Food Research Institute, University of Wisconsin.

[5] Cheesbrough, M. (1999): District laboratory practice in tropical countries part I, Cambridge University Press New York.

[6] Cheesebrough, M. (2004): District Laboratory practice in tropical countries Part 1. (Cambridge University press Pp 2900).

[7] Norhayati, M., Fatmah, M. S., Yusof, S. and Edariah A. B. (2003) Intestinal Parasitic Infections in Man: A Review. Medical Journal of Malaysia, 58 (2). Pp. 296-305.

[8] Wolfe MS. (1992). Giardiasis. Clinical Microbiology Reviews. 5: $93-100$.

[9] Wallis P. M., Erlandsen S. L., Issac-Renton J. L., Olson M. E., Robertson W. J., H. Van Keulen. (1996). Prevalence of Giardia cysts and Cryptosporidium oocysts and characterization of Giardia spp isolated from the drinking water in Canada. Applied and Environmental Microbiology 62: 2789-2797.

[10] Xiao L. (1994). Giardia infection in farm animals. Parasitology Today. 10: 436-438.

[11] Marshall M. M., Naumovitz D., Ortega Y., Sterling C. R. Waterborne protozoan pathogens. Clinical Microbiology Reviews 10: 67-85, 1997.

[12] Magambo J. K; Zeyhl. E and Wachira T. M; 1998 Prevalence of Intestinal parasite among children in southern Sudan. East Africa Med. J. 75 (5): 288-90.

[13] World Health Organization (WHO) (1991). Basic Laboratory Methods in Medical Parasitology. Parasitology - laboratory manuals ISBN 9241544104 (NLM Classification: WC 25).

[14] World Health Organization (WHO) Report (1995). Intestinal parasitic infection 73 92) 183-90. 
[15] World Health Organization (WHO) (1996). Tropical disease research: Progress 1995-96 13th Progress, report. 183-901.

[16] Chandher, A. C. Read, C. P. (1961) Introduction to Parasitology 10th Ed John Wiley and Sons Inc. New York London. P 29.

[17] Stanley, S. J. (2001). Pathophysiology of amoebiasis. Trends Parasitol 17: 280-5.

[18] Tomkins, A, Watson, F. (1989). Malnutrition and infections, Acclscn, Nutrition Policy discussion paper 5, United Nations. New York.

[19] Wagner B; Polly L. (1997). Ascaris suum prevalence and Intensity: an abattoir survey of market hugs in saskatchewen. Veterinary parasitology 73: 309-313.

[20] Morales, G; Pino, L; Perdomo, L. (1986) comparison between the nematodes communities in sheep and goats in the arid zones of venezuela. Mem. Inst. Oswaldo cruz; 81: 185-190.

[21] Crewe W. (1977). A guide of human Parasitology 10th Edition H. K. Lewis and Co. Limited 167-179.

[22] Abdul Ghaffar, (2009), Microbiology and Immunology, 6th edition, University of South Carolina, School of Medicine.

[23] Ali-Ahmad N, Bathija M, Abuhammour W. (2000). Anemia from hookworm infestation. Pediatr Rev 21: 354-7.

[24] Pathak A. K; Pal S. (2008) Seasonal prevalence of Gastrotinal parasites in Goats from Durg District of Chattisgurh Veterinary world 1 (5); 136-137.

[25] Blood D. C; Radostits O. M; Henderson J. A; Arundel J. H; Gay C. C; (1990) Veterinary Medicine. Seventh edition. The English Language Book Society and Bailliere Tindall.

[26] Burton, C. H. Turner, C (2003): Health risks from Pathogens in livestock manure. In manure management. Treatment strategies for sustainable agriculture Ed. Silsoe Research Institute, Uk. Pp 451.

[27] Sadar S. A; Ehsan M. A; Anower A. K. M. M. Rahman M. M. Islam M. A. (2006) Incidence of Liver flukes and Gastrointestinal parasites in Cattle Bangladesh Journal of veterinary Medicine 4 (1): 39-42.

[28] Gajadhar A. A Aramini J. J; Tiffin G; Bisaillon J. R. (1998) Prevalence of Toxoplasma gondii in Canadian age pigs. Journal of parasitology 84: 759-763.

[29] Gamble H. R; Brady R. C; Dubey J. P. (1999) Prevalence of Toxoplasma gondii infection in domestic pigs in the New England States. Veterinary parasitology 82; 759-763.

[30] Davies P. R; Morrow W. E, Deen J; Gamble H. R; Patton S. (1998) Seroprevalence of Toxoplasma gondii and Trichinella spiralis in finishing swine raised in different productions systems in North Carolina, USA. Preventive veterinary medicine. 36: 67-76.

[31] Gaassenbeek C. P. and Borgsteede. F. H. (1998) studies on the survival of Ascaris suum eggs under laboratory and stimulated field conditions. Veterinary Parasitology 75: 227-234.

[32] Guselle N; Olson M. E. (1999) Human pathogens in Alberta flog operations. Alberta pork producers.

[33] Guselle N; Olson M. E. (2000). Are pig parasites a human health risk? Advances in pork production 11: 153-162.
[34] Harold, W. B. Franklin, A. V. (1983): "intestinal nematodes of human beings" Basic clinical parasitology $5^{\text {th }}$ ed. Pp. 105, 142.

[35] Anderson R. C. (1988): Nematode Transmission Pattern Journal of Parasitology 74: 30-45.

[36] Arora (2007): Medical Parasitology 2nd Edition CBS Publishers and Distributors India Pp 1200.

[37] Arora D. R; Arora B (2005) Medical Parasitology CBS Publishers New Delhi India.

[38] Atwill E. R; Sweitzer R. A; Pereira M. G, Gardner J. A; Van V. D; Boyce W. M. (1997) Prevalence and risk factors for shedding Cryptosporidium parvum occyst and Giardia cysts within feral pigs. Applied and environmental microbiology 63: 3946-3949.

[39] Crompton D. W. T., 1992: Ascariasis and Childhood malnutrition. Trans R. Soc. Trop. Med. Hygiene 86; 577-579.

[40] Bethony J, Brooker S, Albonico M, (2006). Soil-transmitted helminth infections: ascariasis, trichuriasis, and hookworm. Lancet. 367 (9521): 1521-32.

[41] Caballero-flemandez A. I, Castrejon-Pineda F. MartineGanaba R. Angeles-Campos, S. Perez-Rojas M; Buntinx S. E, (2004) Survival and viability of Ascaris suum and oesophagostonun dendatum in ensided swine faeces Biores. Tech no. 94: 137-142.

[42] CDC, (2007): Center for diseases control and prevention. Parasitic Disease. 1600 Clifton Rd, Atlantic, 6A 30333. U.S.A. Emailidcinfo@cdc.gov.

[43] Centers for Disease Control and Prevention. Publication of CDC surveillance summaries. Morb Mortal Wkly Rep 41 (8): 145-6.

[44] Corry J. K., Gary L. M. and Brett V. S. (2004). Common Intestinal Parasites. American Academy of Family Physicians Vol. 69/No. 5.

[45] Dickson R, Awasthi S, Demellweek C, Williamson P (2003). Anthelmintic drugs for treating worms in children: effects on growth and cognitive performance. Cochrane Database Syst Rev; (2): CD000371.

[46] Gadahi; J. A, Arshed M. J. AliQ, Javid S. B. shah S. J. (2009) Prevalence of Gastrointestinal parasites of sheep and Goat in and around Rawalpind and Islamabad, Pakistan. Veterinary world 2 (2): 51: 53.

[47] Heyman, D. (1995): Medical parasitology Appleton and Lange 4th Ed U.S.A Pp 3002.

[48] Karanis P, Kourenti C, Smith H. (2007) Waterborne transmission of protozoan parasites: a worldwide review of outbreaks and lessons learnt. J Water Health.; 5: 1-38.

[49] Katoch, R, Chauhan, P. P. S and John D. K. (2000): Indian Vet. J. 77: 259-260.

[50] MacPherson DW (1999). Intestinal parasites in returned travelers. Med Clin North Am; 83: 1053-75.

[51] Olson M. E; Thorlakson C. L. Deselliers L; Morck D. W; Mc Allister T. A (1997) Giadia and Cryptosporidium in Canadian farm animals. Veterinary parasitology 68: 375381. 
[52] Parija SC, Sheeladevi C, Shivaprakash MR, Biswal N. (2001) Evaluation of lactophenol cotton blue stain for detection of eggs of Enterobius vermicularis in perianal surface samples. Trop Doct 2001; 31 (4): 214-5.

[53] Petri WA Jr, Singh U. (1999) Diagnosis and management of amebiasis. Clin Infect Dis 29: 1117-25.

[54] Prevalence of Gastrointestinal parasites in Cattle of Western Vidarbha region. Veterinary World, Vol. 1 (2): 45.

[55] Procop GW. (2001) Gastrointestinal infections. Infect Dis Clin North Am; 15: 1073-108.

[56] Raunelli, F; Gonzalez S (2009) strategic control and prevalence of F. Hepatica in cayarmerca. Peru. A Pilot study. International journal of Applied vertinary medicine. 7 No (4).

[57] Reed, S. L. (2001). Amaebiasis and infection with free-living ameobas. In: Harrison TR, Fauci AS, Braunwald E., eds. Harrison's Principles of internal medicine. 15th ed. New York: McGraw-Hill, 1199-202.

[58] Smyth J. D. (1984): Introduction to animal Parasitology, 2nd ed. Cambridge University Press, Great Britain 22, 48, 181, 205.

[59] Saviroli, L. Bundy, D. Tomkinds, A. (1992) Intestinal parasitic infections: include health problem Trans $R$. Soc. Tropical Medical Hygiene 86: 353-354.

[60] Smyth, J. D. (1990): Animal Parasitology 3rd ed. Cambridge, University Press, Great Britain 25: 269-385.

[61] Saxena AK, Springer A, Tsokas J, Willital GH. (2001) Laparoscopic appendectomy in children with Enterobius vermicularis. Surg Laparosc Endosc Percutan Tech; 11: 284-6. 